\title{
Prevalence and distribution of HPV genotypes among HIV-infected women in Zambia
}

\author{
VV Sahasrabuddhe*,, MH Mwanahamuntu ${ }^{2}$, SH Vermund ${ }^{1,3}$, WK Huh ${ }^{4}$, MD Lyon ${ }^{4}$, JSA Stringer ${ }^{3,4}$ and $^{2}$ \\ GP Parham $2,3,4$
}

'Vanderbilt University, 2215 Garland Avenue, 319 Light Hall, Nashville, TN 37232, USA; ${ }^{2}$ University Teaching Hospital, Nationalist Road, Lusaka, Zambia; ${ }^{3}$ Center for Infectious Disease Research in Zambia, Northmead, Lusaka, Zambia; ${ }^{4}$ University of Alabama at Birmingham, 908-20th Street South, Birmingham, AL 35294, USA

We screened I 45 HIV-infected non-pregnant women at a tertiary care centre in Lusaka, Zambia. Liquid-based cytology and human papillomavirus (HPV) genotyping with PGMY09/I I biotinylated primers (Roche Linear Array ${ }^{\circledR}$ HPV genotyping test) maximised sensitivity of cytology and HPV assessments. Among high-risk (HR) types, HPV 52 (37.2\%), 58 (24. I\%) and 53 (20.7\%) were more common overall than HPV 16 (17.2\%) and 18 (13.1\%) in women with high-grade squamous intraepithelial lesions or squamous cell carcinoma (SCC) on cytology. High-risk HPV types were more likely to be present in women with CD4 ${ }^{+}$cell counts $<200 \mu 1^{-1}$ (odds ratios $(\mathrm{OR}): 4.9,95 \%$ confidence intervals $(\mathrm{Cl}): 1.4-16.7, \mathrm{P}=0.01$ ) and in women with high-grade or severe cervical cytological abnormalities (OR: 8.0, 95\% Cl: I.7-37.4, $\mathrm{P}=0.008$ ). Human papillomavirus diversity in high-grade lesions and SCC on cytology suggests that HPV 16- and I8-based vaccines may not be adequately polyvalent to induce protective immunity in this population. British Journal of Cancer (2007) 96, I480 - | 483. doi:I0.I038/sj.bjc.6603737 www.bjcancer.com

Published online 17 April 2007

(c) 2007 Cancer Research UK

Keywords: human immunodeficiency virus; human papillomavirus; cervical cancer; HPV types; Zambia

Increasing numbers of $\mathrm{HIV}$-infected women in sub-Saharan African settings like Zambia are now accessing life-prolonging antiretroviral therapy (ART) (Stringer et al, 2006). The consequently increasing lifespan may increase their risk of such malignancies as cervical cancer (Strickler et al, 2005). In a crosssectional study among HIV-infected women seeking ART in Lusaka, Zambia, we reported a $79 \%$ prevalence of high-grade squamous intraepithelial lesions (HSIL) of the cervix (Parham et al, 2006). The presence of high-risk (HR) human papillomavirus (HPV) types was independently associated with high-grade cytological lesions (adjusted odds ratios (OR): 12.4, 95\% confidence intervals $(\mathrm{CI}): 2.6-58.1, P=0.02)$. We were able to study HPV genotypes on stored samples from these women.

\section{MATERIALS AND METHODS}

We enrolled 150 consecutive, consenting, non-pregnant HIVinfected Zambian women seeking HIV/AIDS treatment and care at the University Teaching Hospital, the largest tertiary-level care centre in the capital of Lusaka. All women provided written, informed consent and the study was approved by the Research Ethics Committee of the University of Zambia and the Institutional Review Board of the University of Alabama at Birmingham. Participants underwent a complete physical and gynaecological evaluation and cervical samples were collected using Ayre's spatula

*Correspondence: Dr W Sahasrabuddhe;

E-mail: vikrant.sahasrabuddhe@vanderbilt.edu

Received 19 December 2006; revised 12 March 2007; accepted 16 March 2007; published online 17 April 2007 for the ectocervix and cytobrush for the endocervix. Samples were stored in vials containing PreservCyt ${ }^{\mathrm{B}}$ transport medium (Cytyc Corporation, Marlborough, MA, USA) at room temperature $\left(37^{\circ} \mathrm{C}\right)$ for $<2$ weeks before being batch transported for cytological analysis.

Slides prepared from the PreservCyt ${ }^{\mathrm{B}}$ vials were analysed by the liquid-based ThinPrep ${ }^{\mathbb{R}}$ cytological imaging system (Cytyc Corporation, Marlborough, MA, USA). All slides were initially screened by a senior cytotechnologist and all abnormal results and $10 \%$ of negatives were subsequently reviewed by a board-certified cytopathologist. The cytology results were classified and reported as no abnormality detected (normal), atypical squamous cells of undetermined significance (ASCUS), low-grade squamous intraepithelial lesions (LSIL), HSIL and suspicious for squamous cell carcinoma (SCC).

We performed HPV typing by polymerase chain reaction (PCR)based amplification of target DNA using the Linear Array ${ }^{\circledR}$ HPV genotyping test (LA-HPV) (Roche Molecular Systems, Pleasanton, CA, USA), an enhanced and commercialised version of the PGMY line blot assay (PGMY-LB) (Coutlee et al, 2002, 2006; Kornegay et al, 2003). The pool of consensus L1 PGMY09/11 primers used in this assay is designed to amplify HPV-DNA from 37 genotypes. These include HR HPV types $(16,18,26,31,33,35,39,45,51,52$, $53,56,58,59,66,68,73,82)$, low risk (LR) types $(6,11,40,42,54$, $55,61,70,72,81$, and CP6108), and types with unknown risk (UR) $(62,64,67,69,71,83,84$, and IS39). Human papillomavirus types 26,53 , and 66 are usually classified as 'probable' HR types (Munoz et al, 2003), but were grouped with other HR types in this analysis to simplify interpretation.

All participants underwent visual inspection of the cervix with acetic acid and diagnostic colposcopy during the same clinic visit. A CD $4{ }^{+}$cell enumeration was performed with a Beckman Coulter 
Epics XL-MCL 4-color Flow Cytometer (Beckman Coulter Inc. Miami, FL, USA) during the same visit unless a result was available within 3 weeks of the visit date from our rigorously certified laboratory (through the quality assurance programme of the HIV Prevention Trials Network of the National Institute of Allergy and Infectious Diseases, USA).

Using unconditional logistic regression to calculate prevalence OR and 95\% CIs, we compared the type-specific HPV prevalence in HIV-infected women with $\mathrm{CD}^{+}$cell counts $<200 \mu 1^{-1}$ against those of women with $\mathrm{CD} 4{ }^{+}$cell counts $\geqslant 200 \mu \mathrm{l}^{-1}$, the threshold to make clinical decisions for initiating ART in persons without symptoms in Zambia. Similarly, we calculated OR and 95\% CIs for comparing the type-specific HPV prevalence in women with HSIL or SCC on cervical cytology and those with lower grade (ASCUS, LSIL) or no cytologic abnormalities. Statistical analysis was carried out using SPSS 14.0 for Windows ${ }^{\mathrm{TM}}$ (SPSS Inc, Chicago, IL, USA). We restricted our analysis to 145 participants with complete data both on $\mathrm{CD}^{+}{ }^{+}$cell counts and individual HPV genotypes.

\section{RESULTS}

The mean and median ages of these 145 participants were 36.2 years (s.d.: \pm 6.3 ) and 36 years (IQR: $31-41$ ), respectively. About a

Table I Associations between prevalent human papillomavirus (HPV) types and CD4 ${ }^{+}$lymphocyte counts and cervical cytological abnormalities among HIV-infected Zambian women

\begin{tabular}{|c|c|c|c|c|c|c|c|}
\hline \multirow[b]{2}{*}{$\begin{array}{l}\text { HPV-type } \\
\text { categories }\end{array}$} & \multirow[b]{2}{*}{$N(\%$ of 145$)$} & \multicolumn{3}{|c|}{$\mathrm{CD4}^{+}$cell count $<200 / \mu \mathrm{l}(n=9 \mathrm{l})$} & \multicolumn{3}{|c|}{ HSIL or SCC on cytology $(n=77)$} \\
\hline & & HPV +ve & $\begin{array}{l}\text { OR }(95 \% \mathrm{Cl})(\text { compared } \\
\left.\text { to } \mathrm{CD}^{+} \geqslant 200 / \mu \mathrm{l}\right)\end{array}$ & $P$-value & HPV +ve & $\begin{array}{l}\text { OR }(95 \% \mathrm{Cl}) \text { (Compared to LSIL or } \\
\text { less severe lesions on cytology) }\end{array}$ & $P$-value \\
\hline \multicolumn{8}{|c|}{ Presence of various categories of HPV types } \\
\hline Any HR & $131(90.3 \%)$ & 87 & $4.9(1.4-16.7)$ & 0.01 & 75 & $8.0(1.7-37.4)$ & 0.008 \\
\hline Any LR & $87(60 \%)$ & 57 & $1.3(0.67-2.7)$ & 0.4 & 45 & $0.87(0.45-1.7)$ & 0.7 \\
\hline Any UR & $87(60 \%)$ & 60 & $1.9(0.97-3.9)$ & 0.06 & 45 & $0.87(0.45-1.7)$ & 0.7 \\
\hline \multicolumn{8}{|c|}{ Presence of individual high-risk HPV types (in order of decreasing prevalence) } \\
\hline HPV $52^{\mathrm{a}}$ & $54(37.2 \%)$ & 39 & $1.9(0.94-4.0)$ & 0.07 & 32 & $1.5(0.75-2.9)$ & 0.3 \\
\hline HPV 58 & $35(24.1 \%)$ & 24 & $1.4(0.62-3.1)$ & 0.4 & 25 & $2.8(1.2-6.3)$ & 0.02 \\
\hline HPV 53 & $30(20.7 \%)$ & 20 & $1.2(0.53-2.9)$ & 0.6 & 17 & $1.2(0.53-2.7)$ & 0.7 \\
\hline HPV 16 & $25(17.2 \%)$ & 14 & $0.71(0.27-1.9)$ & 0.4 & 17 & $2.1(0.85-5.3)$ & 0.1 \\
\hline HPV 35 & 25 (17.2\%) & 18 & $1.7(0.64-4.3)$ & 0.3 & 14 & I.I $(0.48-2.7)$ & 0.8 \\
\hline HPV 45 & $25(17.2 \%)$ & 19 & $2.1(0.73-6.4)$ & 0.1 & 17 & $2.1(0.85-5.3)$ & 0.1 \\
\hline HPV 39 & $18(12.4 \%)$ & 15 & $3.4(0.92-12.8)$ & 0.07 & 11 & $1.4(0.53-4.0)$ & 0.5 \\
\hline HPV 56 & $18(12.4 \%)$ & 13 & $1.6(0.55-4.9)$ & 0.4 & 11 & $1.4(0.53-4.0)$ & 0.5 \\
\hline HPV 33 & $12(8.3 \%)$ & 10 & $3.2(0.67-15.2)$ & 0.1 & 8 & $1.8(0.53-6.5)$ & 0.3 \\
\hline HPV 59 & $12(8.3 \%)$ & 5 & $0.39(0.12-1.3)$ & 0.1 & 5 & $0.60(0.18-2.0)$ & 0.4 \\
\hline HPV $52^{b}$ & $11(7.6 \%)$ & 8 & $1.6(0.4 \mid-6.5)$ & 0.5 & 4 & $0.48(0.13-1.7)$ & 0.3 \\
\hline HPV 73 & $10(6.9 \%)$ & 7 & $1.4(0.35-5.7)$ & 0.6 & 4 & $0.57(0.15-2.1)$ & 0.4 \\
\hline HPV 26 & $9(6.2 \%)$ & 7 & $2.2(0.43-10.8)$ & 0.4 & 7 & $3.3(0.66-16.5)$ & 0.1 \\
\hline HPV 82 & $7(4.8 \%)$ & 5 & $1.5(0.28-8.1)$ & 0.6 & 5 & $2.3(0.43-12.2)$ & 0.3 \\
\hline \multicolumn{8}{|c|}{ Presence of individual low-risk HPV types (in order of decreasing prevalence) } \\
\hline HPV 6I & $39(26.9 \%)$ & 25 & I.I $(0.50-2.3)$ & 0.8 & 19 & $0.79(0.38-1.6)$ & 0.5 \\
\hline HPV 8I & $26(17.9 \%)$ & 17 & I.I $(0.47-2.8)$ & 0.8 & 14 & $1.0(0.44-2.4)$ & 0.9 \\
\hline CP 6108 & 20 (13.8\%) & 14 & $1.4(0.52-4.0)$ & 0.5 & 9 & $0.69(0.27-1.8)$ & 0.4 \\
\hline HPV 62 & $37(25.5 \%)$ & 24 & I.I $(0.52-2.5)$ & 0.8 & 24 & $1.9(0.88-4.1)$ & 0.1 \\
\hline HPV 84 & $26(17.9 \%)$ & 18 & $1.4(0.57-3.5)$ & 0.5 & 13 & $0.86(0.37-2.0)$ & 0.7 \\
\hline HPV 7I & $23(15.9 \%)$ & 19 & $3.3(1.1-10.3)$ & 0.04 & 14 & $1.5(0.59-3.6)$ & 0.4 \\
\hline HPV 83 & $16(11.0 \%)$ & 11 & $1.3(0.44-4.1)$ & 0.6 & 6 & $0.49(0.17-1.4)$ & 0.2 \\
\hline HPV 55 & $14(9.7 \%)$ & 12 & $3.9(0.85-18.4)$ & 0.08 & 6 & $0.63(0.21-1.9)$ & 0.4 \\
\hline HPV 67 & $9(6.2 \%)$ & 6 & $1.2(0.29-5.0)$ & 0.8 & 5 & I.I (0.29-4.3) & 0.9 \\
\hline IS 39 & $8(5.5 \%)$ & 5 & $0.98(0.23-4.3)$ & 0.98 & 4 & $0.88(0.21-3.6)$ & 0.9 \\
\hline HPV 69 & $2(1.4 \%)$ & । & $0.59(0.03-9.6)$ & 0.7 & । & $0.88(0.05-14.4)$ & 0.9 \\
\hline HPV 64 & $0(0 \%)$ & 0 & - & - & 0 & - & - \\
\hline
\end{tabular}

$\mathrm{HSIL}=$ high-grade squamous intraepithelial lesions; $S C C=$ squamous cell carcinoma; $L S I L=$ low-grade squamous intraepithelial lesions; $H R=$ high-risk $H P V$ types; $L R=$ low-risk HPV types; UR: HPV types of unknown risk. ${ }^{a}$ and ${ }^{b}$ : Probe for detection of HPV 52 cross reacts with HPV 33, 35, and 58. Thus, ${ }^{a}$ is HPV 52 with HPV type 33,35 , and/or 58 coinfection while ${ }^{b}$ is HPV 52 present without any coinfection. 
third (54 out of $145,37.2 \%$ ) were married and cohabiting with their husband, just under a half were educated beyond high school (70 out of $145,48.3 \%$ ) and a majority (84 out of $138,57.9 \%$ ) reported a family income of less than 500000 Zambian kwacha ( US\$110) per month. Little over a third (54 out of 144, 37.2\%) reported their age of first sexual intercourse as less than 18 years, and 116 out of $145(80 \%)$ reported between one and five lifetime sexual partners.

Nine $(6.2 \%)$ women had cytologic results within normal limits. Atypical squamous cells of undetermined significance was reported in $25(17.2 \%)$, LSIL in $34(23.5 \%)$, HSIL in $49(33.8 \%)$, and SCC in $28(19.3 \%)$ participants. Thus $93.8 \%$ of these HIVinfected Zambian women seeking medical care had abnormal Pap smears, $76.6 \%$ had SIL or SCC, and $53.1 \%$ had high-grade SIL or SCC.

Mean and median $\mathrm{CD}^{+}$lymphocyte counts were $208 \mu \mathrm{l}^{-1}$ (s.d.: \pm 177.5 ) and $165 \mu \mathrm{l}^{-1}$ (IQR: $85-299$ ) respectively. Almost two thirds of the participants $(n=91,62.7 \%)$ had a CD4 ${ }^{+}$count $<200 \mu \mathrm{l}^{-1}, 43(29.6 \%)$ had $\mathrm{CD} 4^{+}$counts between $200-499 \mu \mathrm{l}^{-1}$ and $11(7.5 \%)$ had $\mathrm{CD}^{+}$cell counts $\geqslant 500 \mu \mathrm{l}^{-1}$. Validation of results was confirmed with appropriate negative and positive controls for PCR amplification and $\beta$-globin gene detection. Human papillomavirus DNA was detected in 141 out of 145 (97.2\%) participants, while four $(2.8 \%)$ women had no evidence of cervicovaginal HPV DNA. High-risk HPV was detected in 131 (90.3\%) women. We found a single HPV genotype in $14(9.7 \%)$ women and multiple $(\geqslant 2) \mathrm{HPV}$ genotypes in $127(87.5 \%)$ women. The median number of HPV types per woman was 4 (IQR: 2-6), while the mean was 4.4 (s.d.: \pm 2.8 ). Of the $37 \mathrm{HPV}$ types identifiable by the LA-HPV test, all except type 64 were detected in the 145 samples. The test identified 656 distinct HPV infections in 145 women, of which 350 (53.3\%) were HR-HPV while 306 (46.6\%) were LR or UR-HPV types. None of the women carried a HR-HPV type exclusively (i.e. there was always a LR/UR-HPV present if a HR-HPV was present). Among the HR types, HPV 52 was found to be the most prevalent $(37.2 \%)$. However, the probe for detection of HPV-52 amplicons in the LA-HPV test is a cross-reactive probe that also hybridises with types 33,35 , and 58 . It was observed that at least one of these three HR-HPV types was present in $54(37.2 \%)$ samples along with HPV 52, while the latter was present exclusively in $11(7.6 \%)$ samples. Human papillomavirus 58 was present in 35 (24.1\%) and HPV 53 in $30(20.7 \%)$ samples while types 16,35 and 45 were equally common $(17.2 \%)$. Human papillomavirus type 18 (13.1\%) was rank-ordered 10th among high risk types.

Among the 28 women with SCC on cervical cytology, at least one HR-HPV type was present in all women while multiple $(\geqslant 2)$ genotypes were present in $22(78.6 \%)$ women. Human papillomavirus type 52 (mixed probe as described above) was the most prevalent in $13(46.4 \%)$, while types 58 and 16 were present in 10 $(35.7 \%)$. The other HR types in decreasing order of their prevalence in women with SCC on cytology were HPV types 35 (28.6\%), 53 (25\%), 31 and 51 (21.4\% each), 18 and 45 (17.9\% each), $33,56,59$, and 68 (14.3\% each), 39, 36, and 66 (10.7\% each), and 73 (3.6\%). High-risk type 82 was not detected with SCC. Among LR or UR HPV types, types $62,61,70$, and 84 had a prevalence of greater than $15 \%$ in cases with SCC on cytology but none of these types were present exclusively without the concurrent presence of a HRHPV type.

High-risk human papillomavirus types were more likely to be present with $\mathrm{CD} 4{ }^{+}$counts $<200 \mu 1^{-1}$ than with higher counts (OR: 4.9, 95\% CI: $1.4-16.7, P=0.01$ ). Barring HPV 16 and 39, all HR types showed greater prevalence in women with $\mathrm{CD} 4^{+}$counts $<200 \mu 1^{-1}$ but only type 51 achieved statistical significance $(P=0.05)$, given our sample size of 145 . Among HPV-types of UR, HPV 71 was more likely to be present in women with $\mathrm{CD} 4{ }^{+}$ counts $<200 \mu 1^{-1}(P=0.04$; Table 1$)$.

The prevalence of HR-HPV types was higher in women with HSIL or SCC on cervical cytology (OR: 8.0 , 95\% CI: 1.7-37.4, $P=0.008)$. High-risk human papillomavirus 58 and 31 were significantly more likely in women with HSIL or SCC $(P=0.01$ and 0.02 respectively). No other high, low, or UR type was significantly higher in prevalence in women with HSIL or SCC than in other women (Table 1).

\section{DISCUSSION}

The high prevalence of HPV-DNA in our study $(97.2 \%$ for any HPV and $90.3 \%$ for any HR-HPV) is one of the highest reported among an HIV-infected (or any other) population of women worldwide. Also, HPV types 16 and 18 were not the most prevalent HR-HPV types and a relatively high frequency of HPV types 52, 58, $35,53,31,51$, and 45 was observed in women who had HSIL lesions or SCC on cytology. This finding has implications in the eventual implementation of prophylactic HPV vaccines based on HR-HPV types 16 and 18 (Steinbrook, 2006). Our results add to those reported in a recent meta-analysis of HPV types among HIVinfected women (Clifford et al, 2006) and the recent international data which indicate the increased preponderance of HPV types other than 16 or 18 among HIV-infected women (Levi et al, 2002; Bollen et al, 2006; Didelot-Rousseau et al, 2006; Luque et al, 2006). If cross-reacting immunity is not induced across viral types by existing vaccines, this will limit their efficacy in immunosuppressed women in developing countries whose dominant HR-HPV types may be other than 16 and 18 .

We noted that the majority $(87.3 \%)$ of participants carried multiple HPV genotypes and that the mean number of HR types increased with increasing immunosuppression. Comparable studies using PCR-based detection of HPV in HIV-infected women have reported $12-79 \%$ of study participants with multiple HPV types (Levi et al, 2002; Moscicki et al, 2004; Bollen et al, 2006; Didelot-Rousseau et al, 2006; Hawes et al, 2006; Luque et al, 2006). This high prevalence may reflect the immune impairment by HIV that fails to clear HPV, leading to chronic HPV infection. It may also reflect HR sexual practices of some women as in the case of drug users and/or sex workers (Vermund et al, 1991; Shah et al, 1997). If HPV replication is more efficient in an immunocompromised host, the resulting higher viral load will make HPV detection easier and persistence more likely. A higher prevalence of multiple HPV genotypes can result from HIV-induced upregulation and persistence of HPV (Vernon et al, 1993; Palefsky et al, 1999; Moscicki et al, 2004) or from continued sexual exposure to novel HPV types during periods of severe immunosuppression. Not surprisingly, we noted no significant association between LR/UR HPV types and lower $\mathrm{CD}^{+}{ }^{+}$cell counts in our participants, nor any association between LR/UR HPV types and presence of HSIL or severe abnormalities.

The PGMY09/11 primers used in the LA-HPV test have been validated for reproducibility and accuracy in diverse populations (Kornegay et al, 2003; Coutlee et al, 2006). The high-HPV prevalence in our study reflects both the very high sensitivity of the LA-HPV test as well as the extraordinary risk faced by Zambian women living with HIV. The differences in prevalence and diversity of HPV genotypes in HIV-infected women from different geographic origins may be due to their differing behavioural, nutritional, and socioeconomic characteristics or to male factors, as much as to the immunological status of participants. These factors need investigation in larger prospective studies around the world and especially in sub-Saharan Africa where both HIV and cervical cancer rates are high.

The results reinforce the importance of ensuring adequate cervical cancer screening services for HIV-infected women in resource-limited settings like Zambia. They are important given the recent availability of prophylactic HPV vaccines. Considering the diversity of HPV types found, HPV vaccine constructs with polyvalency would be needed for primary prevention of cervical cancer among HR women in developing country settings. 


\section{ACKNOWLEDGEMENTS}

The study was supported in part by a developmental grant from the UAB Center for AIDS Research National Institutes of Health (NIH) Grant P30 AI027767, the AIDS International Training and Research Programs of Johns Hopkins University (NIH Grant D43 TW000010) and UAB (NIH Grant D43 TW001035), NIH Grant R21 CA113465, the Sparkman Center for Global Health of the UAB School of Public Health, and the Vanderbilt University School of Medicine Institute for Global Health. Roche Molecular Systems,

\section{REFERENCES}

Bollen LJ, Chuachoowong R, Kilmarx PH, Mock PA, Culnane M, Skunodom N, Chaowanachan T, Jetswang B, Neeyapun K, Asavapiriyanont S, Roongpisuthipong A, Wright TC, Tappero JW (2006) Human papillomavirus (HPV) detection among human immunodeficiency virus-infected pregnant Thai women: implications for future HPV immunization. Sex Transm Dis 33: $259-264$

Clifford GM, Goncalves MA, Franceschi S, for the HPV and HIV Study Group (2006) Human papillomavirus types among women infected with HIV: a meta-analysis. AIDS 20: $2337-2344$

Coutlee F, Gravitt P, Kornegay J, Hankins C, Richardson H, Lapointe N, Voyer H, Franco E (2002) Use of PGMY primers in L1 consensus PCR improves detection of human papillomavirus DNA in genital samples. J Clin Microbiol 40: $902-907$

Coutlee F, Rouleau D, Petignat P, Ghattas G, Kornegay JR, Schlag P, Boyle S, Hankins C, Vezina S, Cote P, Macleod J, Voyer H, Forest P, Walmsley S, Canadian Women's HIV study Group, Franco E (2006) Enhanced detection and typing of human papillomavirus (HPV) DNA in anogenital samples with PGMY primers and the Linear array HPV genotyping test. J Clin Microbiol 44: 1998-2006

Didelot-Rousseau MN, Nagot N, Costes-Martineau V, Valles X, Ouedraogo A, Konate I, Weiss HA, Van de Perre P, Mayaud P, Segondy M, Yerelon Study Group (2006) Human papillomavirus genotype distribution and cervical squamous intraepithelial lesions among high-risk women with and without HIV-1 infection in Burkina Faso. Br J Cancer 95: 355-362

Hawes SE, Critchlow CW, Sow PS, Toure P, N'Doye I, Diop A, Kuypers JM, Kasse AA, Kiviat NB (2006) Incident high-grade squamous intraepithelial lesions in Senegalese women with and without human immunodeficiency virus type 1 (HIV-1) and HIV-2. J Natl Cancer Inst 98: 100-109

Kornegay JR, Roger M, Davies PO, Shepard AP, Guerrero NA, Lloveras B, Evans D, Coutlee F (2003) International proficiency study of a consensus L1 PCR assay for the detection and typing of human papillomavirus DNA: evaluation of accuracy and intralaboratory and interlaboratory agreement. J Clin Microbiol 41: 1080-1086

Levi JE, Kleter B, Quint WG, Fink MC, Canto CL, Matsubara R, Linhares I, Segurado A, Vanderborght B, Neto JE, Van Doorn LJ (2002) High prevalence of human papillomavirus (HPV) infections and high frequency of multiple HPV genotypes in human immunodeficiency virus-infected women in Brazil. J Clin Microbiol 40: 3341 - 3345

Luque AE, Jabeen M, Messing S, Lane CA, Demeter LM, Rose RC, Reichman RC (2006) prevalence of human papillomavirus genotypes and related abnormalities of cervical cytological results among hiv-1-infected women in Rochester, New York. J Infect Dis 194: $428-434$
Pleasanton, CA provided the LA-HPV PCR kits. Cytyc Corporation, Marlborough, MA provided PreservCyt ${ }^{\circledR}$ transport media and interpreted cytological results by the ThinPrep ${ }^{\mathbb{R}}$ Pap Test. We thank Dr Victor Mudenda of University Teaching Hospital, Lusaka, Zambia for on-site laboratory support and Dr Thomas Broker of UAB for valuable guidance in study design and manuscript preparation.

\section{Conflicts of interests}

The authors state no conflict of interest.
Moscicki AB, Ellenberg JH, Farhat S, Xu J (2004) Persistence of human papillomavirus infection in HIV-infected and -uninfected adolescent girls: risk factors and differences, by phylogenetic type. J Infect Dis 190: $37-45$

Munoz N, Bosch FX, de Sanjose S, Herrero R, Castellsague X, Shah KV, Snijders PJ, Meijer CJ, International Agency for Research on Cancer Multicenter Cervical Cancer Study Group (2003) Epidemiologic classification of human papillomavirus types associated with cervical cancer. N Engl J Med 348: 518-527

Palefsky JM, Minkoff H, Kalish LA, Levine A, Sacks HS, Garcia P, Young M, Melnick S, Miotti P, Burk R (1999) Cervicovaginal human papillomavirus infection in human immunodeficiency virus-1 (HIV)-positive and high-risk HIV-negative women. J Natl Cancer Inst 91: $226-236$

Parham GP, Sahasrabuddhe VV, Mwanahamuntu MH, Shepherd BE, Hicks ML, Stringer EM, Vermund SH (2006) Prevalence and predictors of squamous intraepithelial lesions of the cervix in HIV-infected women in Lusaka, Zambia. Gynecol Oncol 103: 1017-1022

Shah KV, Solomon L, Daniel R, Cohn S, Vlahov D (1997) Comparison of PCR and hybrid capture methods for detection of human papillomavirus in injection drug-using women at high risk of human immunodeficiency virus infection. J Clin Microbiol 35: 517-519

Steinbrook R (2006) The potential of human papillomavirus vaccines. N Engl J Med 354: 1109-1112

Strickler HD, Burk RD, Fazzari M, Anastos K, Minkoff H, Massad LS, Hall C, Bacon M, Levine AM, Watts DH, Silverberg MJ, Xue X, Schlecht NF, Melnick S, Palefsky JM (2005) Natural history and possible reactivation of human papillomavirus in human immunodeficiency virus-positive women. J Natl Cancer Inst 97: 577-586

Stringer JS, Zulu I, Levy J, Stringer EM, Mwango A, Chi BH, Mtonga V, Reid S, Cantrell RA, Bulterys M, Saag MS, Marlink RG, Mwinga A, Ellerbrock TV, Sinkala M (2006) Rapid scale-up of antiretroviral therapy at primary care sites in Zambia: feasibility and early outcomes. JAMA 296: $782-793$

Vermund SH, Kelley KF, Klein RS, Feingold AR, Schreiber K, Munk G, Burk RD (1991) High risk of human papillomavirus infection and cervical squamous intraepithelial lesions among women with symptomatic human immunodeficiency virus infection. Am J Obstet Gynecol 165: $392-400$

Vernon SD, Hart CE, Reeves WC, Icenogle JP (1993) The HIV-1 tat protein enhances E2-dependent human papillomavirus 16 transcription. Virus Res 27: $133-145$ 